\title{
EXAME FÍSICO NA CRIANÇA: UM GUIA PARA O ENFERMEIRO
}

\author{
THE CHILD PHYSICAL EXAM: A GUIDE FOR THE NURSE \\ EXAMEN FÍSICO DEL NIÑO: UNA GUÍA PARA EL ENFERMERO
}

\author{
Josilene de Melo Buriti Vasconcelos ${ }^{1}$ \\ Maria Auxiliadora Pereira ${ }^{2}$ \\ Elizalva Felix de Oliveira ${ }^{3}$
}

\begin{abstract}
RESUMO: O exame físico constitui-se numa importante etapa dentro do processo de avaliação à criança, através do qual o enfermeiro enriquece as informações obtidas durante a entrevista e fundamenta a assistência de enfermagem. Na atualidade, mediante o crescente interesse dos enfermeiros em aplicar o processo de enfermagem em todas as suas etapas, o exame físico tem ocupado lugar de destaque, por permitir que os enfermeiros conheçam as necessidades de seus clientes, no que diz respeito aos seus aspectos físicos e fisiológicos, permitindo a identificação dos diagnósticos de enfermagem, alem de servir como recurso para avaliação efetiva das intervenções de enfermagem. Este estudo, de caráter bibliográfico, objetivou elaborar um guia para realização do exame físico na criança, a ser utilizado por enfermeiros, durante o processo de avaliação à criança. Nele apresentamos o exame físico de forma sistemática, utilizando a seqüência céfalo-caudal, descrevendo os possiveis achados normais e anormais ao examinarmos a criança.
\end{abstract}

PALAVRAS-CHAVE: exame fisico, criança, enfermeiro

\section{INTRODUÇÃO}

Mediante as especificidades dentro de cada faixa etária da criança, o exame físico assume características peculiares, requerendo do enfermeiro, além dos conhecimentos básicos sobre anatomia e fisiologia, conhecimentos sobre crescimento e desenvolvimento infantis, a fim de realizar o exame respeitando as características próprias de cada estágio de desenvolvimento. Tendo em vista a dificuldade de compreensão do que lhe está ocorrendo, o exame físico para a criança pode ser uma situação potencialmente ameaçadora, por ser desconhecido; invasiva do ponto de vista físico e pessoal, e até dolorosa. Diante disso, faz-se necessário que, além das habilidades técnicas, o enfermeiro desenvolva habilidades de comunicação com a criança e com o acompanhante, geralmente a mãe, a fim de facilitar o processo.

O exame físico não se constitui tarefa difícil, embora requeira conhecimento, experiência e treinamento na interpretação dos sinais encontrados a fim de direcionar o processo de decisão do enfermeiro. Neste guia, apresentamos o exame físico de forma sistemática, utilizando a seqüência céfalo-caudal, que deverá ser utilizada pelo enfermeiro mediante seu julgamento sobre o nível de desenvolvimento e as condições da criança, recomendando-se que os procedimentos dolorosos fiquem sempre para o final do exame.

'Enfermeira Assistencial do HULWIPB. Mestre em Enfermagem. Profa da Escola Estadual de Ensino Médio Profissionalizante Prefeito Osvaldo Pessoa. João Pessoa-PB.

${ }^{2}$ Enfermeira. Mestre em Enfermagem. Prof . Assistente III do Departamento de Enfermagem Médico-Cirúrgica e Administração/DEMCAVCCS/UFPB. João Pessoa-PB

${ }^{3}$ Enfermeira. Especialista em Pediatria e Puericultura. Profa da Escola de Enfermagem de Nível Médio/EENM/CCS/UFPB. João Pessoa-PB. 


\section{TÉCNICAS BÁSICAS E MATERIAL NECESSÁRIO PARAAREALIZAÇÃO DO EXAME FÍSICO NA CRIANÇA}

Para realização do exame físico utilizam-se técnicas básicas como inspeção, palpação, percussão e ausculta. Para Ferreira et al. (1995, p.127-34), essas etapas são assim definidas:

Inspeção: compreende o exame visual do paciente cuja finalidade é descobrir características físicas significativas. Compreende observações precisas e detalhadas, unidas à comparação com os padrões de normalidade, da aparência geral da área examinada além das características específicas como cor, textura, localização, posição, tamanho, tipo e grau de movimento, simetria e comparação com o lado oposto.

Palpação: é o processo de examinar o corpo, empregando o sentido do tato com o objetivo de determinar as características dos órgãos e dos tecidos. Utiliza-se a capacidade tátil, térmica, vibratória e de pressão das mãos para detectar temperatura, movimento, posição, consistência e forma.

Percussão: consiste em golpear a superfície do corpo de forma rápida, porém aguda, para produzir sons que permitam ao examinador determinar posição, tamanho, densidade de uma estrutura adjacente.

Ausculta: Consiste em escutar os sons produzidos pelos diferentes órgãos do corpo com o objetivo de descobrir variações e desvios de suas características. Pode ser efetuada por método direto, colocando-se o ouvido diretamente na pele (pouco eficaz) e indireto, com o auxílio do estetoscópio.

A utilização dessas técnicas durante o exame físico permite a identificação de sinais e sintomas, característicos das condições fisiológicas da criança, os quais não devem ser compreendidos isoladamente, mas a partir do conjunto de dados obtidos, inclusive os da entrevista, tendo como base um referencial para identificação de diagnósticos de enfermagem, tal como a Taxonomia I Revisada da NANDA e Uniformizada no Brasil, conforme Nóbrega e Garcia (1994).

O material necessário para a realização do exame físico na criança consiste basicamente do seguinte: mesa, antropômetro manual (crianças até $100 \mathrm{~cm}$ ); balança (pesa-bebê: até $16 \mathrm{Kg}$; antropométrica com toesa vertical: acima de $16 \mathrm{Kg}$ e de $100 \mathrm{~cm}$ ); estetoscópio e esfigmomanômetro; termômetro; fita métrica; espátulas (abaixador de língua); lanterna; bolas de algodão; álcool; papel toalha; brinquedos ou outros recursos adequados à idade (a fim de obter a colaboração da criança).

\section{ROTEIRO DO EXAME FÍSICO NA CRIANÇA: SEQÜENCIA CÉFALO-CAUDAL}

\section{1 - OBSERVAÇÃO DAAPARÊNCIA GERAL}

Registra-se a primeira impressão sobre a criança a ser examinada. Envolve a observação da fisionomia (mostra-se alegre ou triste, calma ou agitada, assustada, irritada), interação com o meio (atividade: hipo, normo ou hiperativa; resposta aos estímulos ambientais e interação com as pessoas: comunicativa, apática, interessada, desinteressada, brincando, retraída), postura (ereta, relaxada, encolhida, de proteção de uma área do corpo dolorida ou incômoda), se exibe traços característicos ou deformidades físicas, estado nutricional (obesa, emagrecida, caquética) e de hidratação (hidratada, desidratada), condições de higiene e vestuário.

\section{2- PELE EANEXOS \\ Cor:}

Achado normal: pele corada. 
Achados anormais: palidez, cianose, icterícia (exceto a icterícia fisiológica do recém-nascido, que se instala cerca de vinte e quatro horas após o parto desaparecendo na segunda semana), pele acinzentada ou marmórea, ausência de pigmentação (vitiligo).

Textura:

Achados normais: a pele deve ser lisa, macia e flexivel.

Achados anormais: pele áspera, seca, rugosa (devido banhos freqüentes, exposição ao frio, hipovitaminose A) ou descamativa (observar descamação entre os artelhos pode ser micose; na planta dos pés; na região perianal e perineal, pode ocorrer após o exantema das fraldas); crianças obesas podem apresentar estrias no abdome e nas coxas.

Temperatura:

Achado normal: temperatura compativel com a temperatura ambiental.

Achados anormais: hipertermia ou hipotermia localizadas ou generalizadas.

Turgor.

Achado normal: pele elástica.

Achado anormal: elasticidade diminuída ou aumentada. Na presença de edemas registrar se é generalizado ou localizado (citar a região), se é depressivel ou não depressível.

Umidade:

Achados normais: presença de sudorese a partir de um mês de vida.

Achados anormais: sudorese excessiva (que pode ser devido temperatura elevada, excesso de agasalho, pelo choro ou pelo ato de comer) ou ressecamento de pele.

Integridade:

Achado normal: Pele íntegra isenta de lesões ou sinais de inflamação.

Achados anormais: presença de lesões, classificadas por Sigaud e Veríssimo (1996, p. 168) em primárias (mácula, mancha, pápula, vesícula, bolha, pústula, nódulo, tumor, cisto, petéquia, equimose ou hematoma) ou secundárias (escama, crosta, úlcera, fissura, escoriação, cicatriz, quelóide, ou sinais de inflamação (rubor, calor, edema e dor).

Outros achados: xantomas, miliáreas, manchas mongólicas, erytema toxicum neonatorum, eritema, hemangiomas.

Unhas:

Achados normais: leitos ungueais rosados, unhas convexas, lisas e duras, mas flexiveis; bordas cobrindo a extremidade dos dedos. 
Achados anormais: cianose, leitos ungueais escurecidos (porfiria, traumatismos), unhas escavadas (onicomicose), onicofagia, celoniquia, paroníquia (infecção ao redor da unha), unhas em garra (característico da hanseniase), unhas quebradiças.

Pêlos corporais:

Achados normais: presença de lanugem no recém-nascido, surgimento dos pêlos secundários com a puberdade. Devem ter distribuição regular e serem isentos de sujidades e infestações (piolhos, lêndeas, carrapatos, fungos).

Achados anormais: hisurtismo, hipertricose, tufos de pêlos, pêlos acentuadamente frágeis ou ásperos, aparecimento precoce ou retardado dos pêlos secundários.

\section{MEDIDAS DE CRESCIMENTO}

Para verificação da altura e perímetro cefálico $(\mathrm{PC})$ deve ser utilizado um parâmetro para interpretação. Recomendamos a utilização dos parâmetros do National Center for Health Statistics - NCHS para a idade (Thompson e Ashwill, 1996, p.412-19).

Achados normais: medidas de crescimento compativeis com o estágio de desenvolvimento.

Achados anormais: desvios nos padrões normais de desenvolvimento esperados para a idade.

\section{4 - SINAIS VITAIS}

Verificar os sinais vitais (freqüência respiratória, pulso radial, pressão arterial e temperatura) e comparar com os padrões normais para idade, registrando os locais de verificação e características. Para padrões de comparação dos sinais vitais recomendamos como Fontes: Sigaud e Verissimo (1996, p.261-63), Seibert (1995, p.235-46), Thompson e Ashwill (1996, p.31-33), respectivamente.

\section{5 - CABEÇA:}

Crânio:

Achados normais: proeminências frontais, parietais e occipitais simétricas, perímetro cefálico compativel com a idade (normocefalia), suturas e fontanelas compativeis com a idade. O couro cabeludo deverá ser brilhante, sedoso, firme e elástico, limpo e isento de infestações e lesões. Os cabelos podem apresentar variações de cor de acordo com as características genéticas (louros, castanhos, negros, ruivos).

Achados anormais: macro-microcefalia, proeminências ósseas assimétricas, suturas abertas após o sexto mês de vida, oclusão precoce ou tardia das fontanelas, fontanelas deprimidas ou abauladas; presença de lesões, descamações, infestações, evidências de traumatismos (equimoses, massas ou cicatrizes) no couro cabeludo. Cabelos pegajosos, opacos, ressecados, quebradiços e despigmentados, calvície ou áreas ralas, alopecia, presença de sujeira, odor desagradável e infestações.

Face:

Achados normais: traços fisionômicos normais, proporções características, simetria, movimentação e tônus muscular normais. 
Achados anormais: assimetria, fácies típica (fácies renal, mixedematosa, acromegálica, Cushing, mongolóide), testa pequena ou aumentada, implantação anormal das orelhas, nariz em sela, lábio leporino, micrognatia (queixo acentuadamente pequeno), paralisias, protrusão da lingua, mímica facial aumentada (tiques nervosos) ou diminuida.

Olhos:

Achados normais: tamanho e distância proporcional, simetria; pálpebras suficientes para fechar o olho, pestanejamento normal, ausência de lesōes e sinais de infecções e parasitos; cílios com pigmentação, quantidade e distribuição adequadas; lacrimejamento normal; conjuntiva palpebral rosa e acetinada, conjuntiva bulbar transparente; esclerótica branca, ligeiramente azulada (em recém-nascidos), levemente parda com pontos escuros (em crianças de pele escura); córnea clara, transparente e brilhante; pupilas iguais (isocóricas), redondas, reagir à luz e à acomodação; movimentos oculares coordenados.

Achados anormais: microftalmia, hipertelorismo, hipotelorismo, exoftalmia, enoftalmia; ptose, ambliopia, blefaropasmoectropia, entropia, pregas epicânticas, edemas; ausência parcial ou total ou distribuição irregular dos cílios; lacrimejamento ausente ou exagerado, sinais de infecção (ardor, calor, prurido, aspecto nodoso, edema, hiperemia, secreção serosa ou purulenta); hordéolos, calázios ou cistos de Meibom, furúnculos, antrazes, blefarite marginal, presença de lêndeas ou piolhos nas pálpebras, geralmente procedentes da cabeça, palidez na conjuntiva palpebral, icterícia, manchas hemorrágicas; opacidades, turvações e ulceraçöes; anisocoria, midriase, miose; estrabismo convergente ou divergente; nistagmo.

\section{Ouvidos:}

Achados normais: pavilhão auricular presente, implantação normal, tamanho proporcional, ausência de lesões e sujeiras; presença de cerume amarelo-claro e macio no canal auditivo médio; ausência de sinais de infecção; reflexo de Moro presente no recém-nascido.

Achados anormais: malformaçōes (ausência de pavilhão auricular), orelhas em desnivel, protrusão em relação ao couro cabeludo, tamanho desproporcionalmente menor (microtia) ou maior (macrotia); cerume escuro e endurecido, secreção, odor desagradável; presença de furúnculos e corpos estranhos; ausência do reflexo de Moro no recém-nascido, inexistência de indícios de capacidade auditiva em crianças maiores.

Nariz:

Achados normais: localização na linha média da face, logo abaixo dos olhos e acima dos lábios, narinas simétricas, ausência de movimentos oscilatórios das asas do nariz, mucosas integras e normalmente mais vermelhas que a mucosa oral, fossas nasais permeáveis, ausência de secreções, sujeiras e corpos estranhos.

Achados anormais: desvio do septo nasal, assimetria na forma global e diâmetro das narinas, desvio de septo nasal, batimentos de asas do nariz, edemas, secreções, ressecamento, hemorragia, sujeiras, obstrução nasal, presença de corpos estranhos.

Boca:

Achados normais: lábios úmidos, macios, lisos e rosados, com tonalidade um pouco mais 
escura que a pele adjacente, simétricos quando contraídos ou relaxados; mucosa oral rosabrilhante, lisa, uniforme e úmida, com odor agradável; gengivas com textura característica e firmes, lisas e rosadas, isentas de lesões, podem apresentar áreas doloridas, edemaciadas e esbranquiçadas devido à erupção dentária; dentição compatível com a idade (recomendamos Thompson e Ashwill (1996, p.141) para cronologia da erupção dentária), dentes íntegros, limpos, de cor variável entre branco ou levemente amarelados, alinhados, com oclusão normal; língua com tamanho e mobilidade normais (normalmente a ponta da língua deve chegar até os lábios), presença de papilas linguais que conferem aspecto rugoso característico, fissuras linguais transversais (língua escrotal que se constitui numa variedade normal), freio lingual normal; palato duro, palato mole e úvula íntegros, movimento da úvula para cima, separando a nasofaringe da orofaringe; amígdalas facilmente observáveis sobre os arcos palatoglóssicos, apresentando a mesma cor que a mucosa adjacente, com aparência mais glandular do que lisa; ausência de sinais de inflamação e infecção.

Achados anormais: quelite (secura, aspereza e descamação), estomatite angular ou "boqueira"; mucosa oral descorada, com regiões de placas esbranquiçadas ou ulcerações, sangramento, áreas dolorosas, halitose; dentição precoce, retardada ou ausente, dentes quebrados, desgastados, desalinhados, mal ocluídos, sujos e cariados; macroglossia ou microglossia, fissuras linguais longitudinais, tremores da língua, freio lingual curto e fibroso; fenda palatina, úvula bífida, amígdalas ausentes, sinais de inflamação e infecção, placa de secreção recobrindo amígdalas e cercanias (placa diftérica).

\section{6 - PESCOÇO}

Achados normais: simétrico em todos os ângulos (nos lactentes, curto com dobras cutâneas entre a cabeça e os ombros, alongando-se a partir dos três ou quatro anos); movimentação livre, sustentar a cabeça com firmeza a partir dos três meses; traquéia palpável na linha mediana; tireóide palpável com massa lisa e sólida que se move para cima com a deglutição (difícil de ser palpada nos lactentes), nódulos linfáticos não palpáveis ou pequenos, macios, redondos e indolores à palpação, pulsações regulares.

Achados anormais: movimentação limitada, sustentação da cabeça deficiente, torcicolo, opistótono, desvios da traquéia ou presença de massas no pescoço, nódulos linfáticos aumentados, endurecidos e doloridos, pulsações excessivas.

\section{7 - TÓRAX}

\section{Caixa torácica:}

Achados normais: nos lactentes tem forma circular, mas à medida que a criança cresce, o tórax aumenta em direção transversa, o que torna o diâmetro antero-posterior menor do que o lateral; mobilidade da parede torácica bilateralmente simétrica e coordenada; perímetro torácico (PT) compativel com a idade.

Achados anormais: tórax típico (careniforme, em funil, em barril), rosário raquítico, perímetro torácico incompativel com a idade da criança ou desproporcional ao perímetro cefálico.

Coluna vertebral:

Achado normal: alinhada. 
Achados anormais: desvio lateral (escoliose), acentuação da curva lombar (lordose), acentuação da curva dorsal (cifose).

Mamas:

Achados normais: presença de dois mamilos com distância menor ou igual a 1/4 do PT, desenvolvimento compativel com a idade, ausência de anormalidades (massas, nódulos).

Achados anormais: mamilos extranumerários, distância irregular, mamas assimétricas, presença de fissuras, inversões, descamação, nódulos. Nas púberes/adolescentes a realização da palpação das mamas e região axilar é muito importante, pois além de permitir identificar anormalidades, permite orientar quanto à prática do auto-exame nas mesmas.

\section{Sistema respiratório:}

Achados normais: movimentos respiratórios e freqüência respiratória compativeis com a idade, ritmo respiratório normal (eupnéia), ausência de sinais de desconforto respiratório; expansibilidade torácica com movimentos simétricos das mãos durante a verificação da expansibilidade pulmonar; frêmitos presentes, com variações nas diversas zonas do tórax; murmúrios vesiculares audiveis por toda a superficie dos pulmões, com exceção do espaço interescapular superior e sobre o manúbrio; murmúrios brônquicos audiveis sobre a traquéia, murmúrios bronquiovesiculares ouvidos sobre a região do brônquio principal, especificamente na região interescapular e de cada lado do esterno.

Achados anormais: movimentos respiratórios incompativeis com a idade, ritmo respiratório irregular (taquipnéia, bradpnéia, respiração Cheyne-stokes, respiração Kussmaul, ritmo de Biot), apnéia; respiração superficial ou profunda; sinais de desconforto respiratório (dispnéia, batimentos das asas do nariz, retrações ou tiragens nas regiões intercostais, supraestemal, supraclavicular e diafragmática, inquietação, prostração, palidez, cianose, ortopnéia); dor relacionada com movimentos respiratórios, presença de tosse (seca, produtiva) e secreção nas vias aéreas (mucosa, purulenta), hemoptise; movimentos assimétricos na expansibilidade torácica; frêmitos tóraco-vocal ausentes, enfraquecidos ou aumentados, vibrações diferentes em áreas simétricas do tórax; murmúrios vesiculares, brônquicos e bronquiovesiculares fora das áreas consideradas normais; murmúrios respiratórios diminuidos ou ausentes, presença de ruídos adventícios estertores e roncos.

\section{Sistema cardiovascular:}

Achados normais: batimentos cardiacos nítidos e claros nos quatro focos de ausculta (aórtico, pulmonar, tricúspide e mitral), freqüência compatível com a idade e com o pulso radial, rítmico ou regular. Perfusão sangüínea periférica presente, boas condições dos vasos sangüineos, ausência de circulação colateral.

Achados anormais: batimentos cardiacos abafados, difusos ou distantes, freqüência incompativel com a idade e com o pulso radial (taquicardia, bradicardia), arrítmico ou irregular. Perfusão sangüínea periférica diminuída ou ausente, presença de estase jugular, circulação colateral, sinais de infecção vascular, sinais de desconforto (adoção freqüente da posição genupeitoral durante o sono e de cócoras quando em atividade, hipoatividade, cansaço aos menores esforços, palidez, cianose, sudorese, edemas, dificuldade respiratória, retardo no crescimento e desenvolvimento). 


\section{8. $A B D O M E$}

Achados normais: movimentos respiratórios visiveis, em sincronia com os movimentos torácicos, abdome flácido, simétrico, pele uniformemente esticada e sem pregas, umbigo plano ou ligeiramente protruso, cicatriz umbilical seca, epitelizada, com formação de fossa umbilical, isento de sinais de infecção e de sujeira; presença de peristaltismo intestinal e com características normais evidenciados através de ruidos que se assemelham a curtos cliques metálicos ou borbulhas; sons característicos: macicez (sobre o lado direito, ao nivel do rebordo costal, provindo da presença do fígado), timpanismo (à esquerda, sobre o estômago e, em geral, no restante do abdome); abdome flácido e relaxado, isentos de massas, órgãos dentro da normalidade, os pulsos femorais devem ser palpados simultaneamente a fim de certificar-se de sua sincronia $e$ normalidade.

Achados anormais: assincronia entre os movimentos respiratórios abdominais e torácicos, abdome globoso, volumoso, assimétrico, com abaulamento localizado, evidências de anormalidades na região umbilical (hérnias, fistulas, umbigo cutâneo, umbigo amniótico, umbigo evertido, granuloma umbilical), sinais de infecção (área periumbilical rubra, quente, endurecida, presença de secreção pútrida, retardo na queda do coto e na cicatrização), higiene insatisfatória; peristaltismo diminuido, ausente (ileo paralitico), ou aumentado (hiperperistaltismo); timpanismo exagerado assemelhando-se a batidas de um tambor, macicez mutável (pode indicar ascite); abdome tenso, distendido, presença de hiperestesia cutânea, presença de massas, hérnias (umbilicais e inguinais), evidência de infartamento ganglionar na região inguinal, órgãos aumentados de tamanho, pulsos femorais assincrônicos, diminuidos ou ausentes.

\section{GENITÁLIA \\ masculina:}

Achados normais: órgão genital compativel com a idade, meato urinário centralizado na glande, tamanho normal, isenta de lesões e secreções, testículos no interior da bolsa escrotal, ambos com o mesmo tamanho, surgimento de pêlos pubianos com a puberdade.

Achados anormais: hipoplasia peniana (microfalo) ou hiperplasia (megalopênis), fimose, parafimose, hipospádia, epispádia, criptorquidia uni ou bilateral, ectopia testicular, testículos aumentados (geralmente por edema) quando ficam com a pele lisa e brilhante; presença de pêlos lanuginosos e macios na base do pênis, antes da puberdade, os quais podem se constituir num sinal de maturação sexual precoce.

\section{Feminina:}

Achados normais: formação anatômica normal, pequenos lábios compativeis com a idade (hipertrofiados em recém-nascidos, atrofiados na criança, desenvolvidos a partir da puberdade), canal vaginal presente com abertura vaginal coberta pelo himen (ausente após as relações sexuais), surgimento dos pêlos pubianos a partir da puberdade, ausência de sangramentos vaginais, exceto o normal advindo da menstruação, meato urinário entre a vagina e o clitóris, ausência de sinais de infecção e traumas.

Achados anormais: formação anatômica anormal, desenvolvimento sexual incompativel com a idade, aparecimento precoce ou tardio dos pêlos pubianos com distribuição irregular, 
sangramentos anormais, sinais de infecção (presença de secreção purulenta e fétida, hiperemia, prurido, ardor), sinais de traumas (hematomas, sangramento, lesões, dor).

10. ÂNUS

Achados normais: orifício anal presente, íntegro, isento de sinais de parasitoses, presença de reflexo esfincteriano (contração anal).

Achados anormais: ânus imperfurado, com hemorróidas ou varizes perianais, fissuras ou prolapso retal, ausência de reflexo esfincteriano, sinais de parasitoses (prurido, escoriações, hiperemia ou presença de parasitos na região anal e perianal).

\section{MEMBROS}

Achados normais: conformação óssea normal, simétricos em comprimento e largura, com movimentação ampla, harmoniosa e compatível com a idade.

Achados anormais: evidências de fraturas, luxações, entorses, ausência de membros, polidactilia, sindactilia, genu varum, genu valgum, pé varo, pé valgo, pé chato ou plano, pé eqüino, movimentos articulares diminuídos ou sinais de inflamação localizada nas articulações, presença de luxação congênita em recém-nascidos.

\section{SISTEMA NEUROMUSCULAR}

Achados normais: criança alerta (resposta a estímulcs do ambiente), atividade compativel com o seu padrão habitual e a fase de desenvolvimento em que se encontra, orientada no tempo e no espaço, reconhecendo pessoas e objetos familiares, reflexos compatíveis com a idade; músculos eutróficos, com tônus e movimentos voluntários normais.

Achados anormais: criança sonolenta, com diminuição do nível de consciência ou inconsciente, hipoativa, hiperativa, desorientada (não reconhece pessoas e objetos que Ihe são familiares), com delírios (vive situação imaginária ou falsa), com alucinações (falsas percepções sensoriais), reflexos incompativeis para a idade; músculos atrofiados ou hipertrofiados, hipotônicos, hipertônicos, movimentos musculares voluntários diminuidos ou ausentes, presença de tremores ou espasmos (involuntários). Para a avaliação dos principais reflexos do recém-nascido e latente recomendamos como fontes: Alexander e Brown (1987), Whaley e Wong (1989, p.79-119), Sigaud e Veríssimo (1996, p.20).

\section{AVALIAÇÃO DO DESENVOLVIMENTO}

Este se constitui num dos componentes essenciais para avaliação completa da saúde infantil e deve ser realizada a partir de um parâmetro de observação. Recomendamos o Teste de Denver que se propõe a esse objetivo (Thompson e Ashwill, 1996, p.420).

\section{CONSIDERAÇÕES FINAIS}

A importância deste guia para a área assistencial parte da premissa de que a indicação precoce de sinais e sintomas para a criança facilita o planejamento da assistência, permitindo ao enfermeiro selecionar ações de enfermagem apropriadas às reais necessidades da criança que requer uma assistência individualizada, independente e qualificada, considerando as peculiaridades inerentes ao processo de crescimento e desenvolvimento. 
Diante disso, recomenda-se que o exame físico seja incorporado a prática da enfermeira pediátrica com vistas a melhorar a qualidade da assistência prestada, oferecendo a oportunidade de viabilizar, na prática, o processo de enfermagem em todas as suas etapas e, conseqüentemente, tornando o seu trabalho visivel e definindo o seu papel junto a outros profissionais de saúde.

ABSTRACT: The physical exam is constituted inside in an important stage of the evaluation process to the child, through which the nurse enriches the information obtained during the interview and it bases the nursing care. At the present time, by means of the nurses growing interest in applying the nursing process in whole its stages, the physical exam has been occupying prominence place, for allowing the nurses to know the its customers' needs, in what says respect to its physical and physiologic aspects, allowing the identification of the nursing diagnoses, besides serving as resource for evaluation effective of the nursing interventions. This study, of bibliographical character, objectified to elaborate a guide for accomplishment of the physical exam in the child, to be used by nurses, during the evaluation process to the child. In him we presented the physical exam in a systematic way, using the sequence cephalic-flow, presenting the possible normal and abnormal discoveries to the we examine the child.

KEYWORDS: physical exam, child, nurse

RESUMEN: El examen fisico se constituye una importante etapa dentro del proceso de evaluación del niño, pues el enfermero enriquece las informaciones obtenidas durante la entrevista y fundamenta la asistencia de enfermería. Actualmente, debido al creciente interés de los enfermeros en aplicar el proceso de enfermeria en todas sus etapas, el examen físico está ocupando un lugar destacado, al permitir que los enfermeros conozcan las necesidades de sus clientes, respecto a aspectos físicos y fisiológicos, para permitir la identificación de los diagnósticos de enfermería, además de servir como recurso para una evaluación efectiva de las intervenciones de enfermeria. El estudio -de carácter bibliográfico- busca elaborar una guia para que sirva a los enfermeros cuando le van a hacer el examen físico al niño, a fin de evaluarlo mejor. Se presenta el examen fisico de forma sistemática, utilizando la secuencia céfalo-caudal y se describen los posibles datos normales o anormales al examinar al niño.

PALAVRAS CLAVE: examen físico, niño, enfermero

\section{REFERÊNCIAS BIBLIOGRÁFICAS}

ALEXANDER, M.M., BROWN, M.S. Diagnóstico na enfermagem pediátrica. São Paulo: Andrei, 1987. $289 p$.

FERREIRA, S.L. et al. O exame físico como parte integrante da avaliação sistemática de enfermagem. In: SCHMITZ, E.M.R. Enfermagem em pediatria e puericultura. São Paulo: Atheneu, 1995. Cap.10, p. $127-134$.

NÒBREGA. M.M.L., GARCIA, T.R. (org.) Uniformização da linguagem dos diagnósticos de enfermagem da NANDA: sistematização das propostas do II SNDE. João Pessoa: A União, 1994. 138p.

SEIBERT, E.R.C. Verificação de sinais vitais em pediatria. In: SCHMITZ, E.M.R. Enfermagem em pediatria e puericultura. São Paulo: Atheneu, 1995, cap.21, p. 235-247.

SIGAUD, C.H.S.; VERISSIMO, M. de Lá Ó R. Enfermagem pediátrica. São Paulo: EPU, 1996. 269p.

THOMPSON, E.D.; ASHWILL, J.W. Uma introdução à enfermagem pediátrica. 6.ed. Porto Alegre: Artes Médicas, 1996. 446p.

WHALEY, L.F.; WONG, D.L. Enfermagem Pediátrica: elementos essenciais à intervenção efetiva. 2.ed. Rio de Janeiro: Guanabara, 1989. 910p. 